
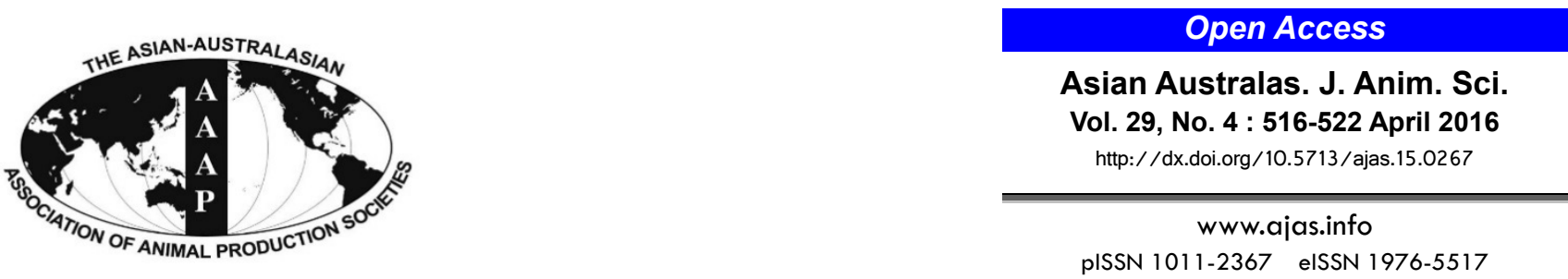

\title{
Lactic Acid Bacteria in Total Mixed Ration Silage Containing Soybean Curd Residue: Their Isolation, Identification and Ability to Inhibit Aerobic Deterioration
}

\author{
Y. Li*, F. Wang ${ }^{1}$, and N. Nishino ${ }^{2}$ \\ College of Animal Science and Veterinary Medicine, Heilongjiang Bayi Agricultural University, \\ Daqing, Heilongjiang 163319, China
}

\begin{abstract}
We investigated the effects of the predominant lactic acid bacteria (LAB) on the fermentation characteristics and aerobic stability of total mixed ration (TMR) silage containing soybean curd residue (SC-TMR silage). The SC-TMR materials were ensiled in laboratory silos for 14 or 56 days. LAB predominant in SC-TMR silage were identified (Exp. 1). Lactobacillus fermentum (L. fermentum) and Streptococcus bovis (S. bovis) were found in the untreated materials, Leuconostoc pseudomesenteroides (L. pseudomesenteroides) in 14-day silage and Lactobacillus plantarum (L. plantarum) in all silages. Pediococcus acidilactici (P. acidilactici), Lactobacillus paracasei (L. paracasei), and Lactobacillus brevis (L. brevis) formed more than $90 \%$ of the isolates in 56day silage. Italian ryegrass and whole crop maize were inoculated with $P$. acidilactici and $L$. brevis isolates and the fermentation and aerobic stability determined (Exp. 2). Inoculation with P. acidilactici and L. brevis alone or combined improved the fermentation products in ryegrass silage and markedly enhanced its aerobic stability. In maize silage, $P$. acidilactici and $L$. brevis inoculation caused no changes and suppressed deterioration when combined with increases in acetic acid content. The results indicate that $P$. acidilactici and L. brevis may produce a synergistic effect to inhibit SC-TMR silage deterioration. Further studies are needed to identify the inhibitory substances, which may be useful for developing potential antifungal agents. (Key Words: Soybean Curd Residue-Containing TMR Silage, Aerobic Deterioration, Lactic Acid Bacteria, Synergistic Effect)
\end{abstract}

\section{INTRODUCTION}

Total mixed rations (TMR) silage is an important source of ruminant feed. A practice in Japan is to mix wet byproducts (e.g. brewers' grains [BG], soybean curd residue $[\mathrm{SC}]$, rice bran and beet pulp) with dry feeds to prepare low-moisture TMR which are then preserved as silage. Wet BG and SC are often used as the main ingredients with other feedstuffs being added in lower proportions. High aerobic stability was found in TMR silage regardless of bacterial inoculant and ensiling period. The aerobic stability

\footnotetext{
* Corresponding Author: Y. Li. Tel: +86-459-6819002, Fax: +86459-6819015, E-mail: yanbing_894@hotmail.com

${ }^{1}$ Department of Animal Science, Dalian Medical University, Dalian, Liaoning, 116044, China.

${ }^{2}$ Department of Animal Science, Graduate School of Natural Science and Technology, Okayama University, Okayama 7008530, Japan.

Submitted Mar. 27, 2015; Revised Jun. 11, 2015; Accepted Jun. 24, 2015
}

of silage is of great importance because of the consequent losses of nutrients and dry matter (DM) and the development of molds which can produce mycotoxins, a health hazard for animals and humans (Driehuis and Elferink, 2000). Based on conventional criteria, aerobic deterioration could occur easily in TMR silage, because lactic acid prevails during fermentation and any sugars remaining unfermented can serve as substrates for the growth of yeasts. According to our previous study, aerobic deterioration occurred immediately when BG was ensiled alone, but when it was stored as TMR silage no heating occurred for 7 days (Nishino et al., 2003a). Resistance to spoilage through heating was also shown when wet BG was replaced with SC (Wang and Nishino, 2008a).

We have performed several studies to investigate the factors associated with the aerobic stability of TMR silage. The predominant lactic acid bacteria (LAB) were responsible for silage fermentation and had the greatest influence on silage preservation. In BG-containing TMR 
silages, we detected a small amount of 1, 2-propanediol and isolated Lactobacillus buchneri (L. buchneri) as the predominant LAB (Nishino et al., 2004; Nishino et al., 2007; Wang and Nishino, 2008b). L. buchneri could be related to resistance to spoilage, but was not detected in SCcontaining TMR silage (Wang and Nishino, 2008a). This shows the need to understand why SC-containing TMR silage can resist deterioration regardless of detectable yeast numbers, because SC is more difficult to ensile alone than BG. Aerobic bacteria may grow rapidly and spoilage would occur soon after exposure to air (Niwa, 2001).

The aim of the present study was to evaluate the effects of the predominant LAB in SC-TMR silage on its fermentation and aerobic stability. We used two laboratoryscale experiments: in Exp. 1, we performed cultureindependent analysis to identify the bacterial communities associated with ensiling of SC-containing TMR silage to be used as inoculants in Exp. 2. In Exp. 2, an inoculation study was conducted using Italian ryegrass silage and whole crop maize silage to evaluate the effect on resistance to aerobic deterioration.

\section{MATERIALS AND METHODS}

\section{Ensiling}

Experiment 1: Wet SC was obtained from a local factory and ensiled within $6 \mathrm{~h}$ of production. A TMR was formulated with SC, alfalfa hay, sudangrass hay, cracked corn, wheat bran, soybean meal, dried beet pulp and molasses by mixing in a ratio of $25: 2.5: 2.5: 5: 5: 1: 5: 4$ on a fresh weight basis. A $300 \mathrm{~g}$ portion of TMR mixture was ensiled in a laminated plastic pouch (Hiryu BN-12, Asahi Kasei Pax, Tokyo, Japan) and then tightly packed using a commercial vacuum sealer (SQ-303, Asahi Kasei Pax, Japan). Silages were made in triplicate and stored at ambient temperature for 14 or $56 \mathrm{~d}$. The same materials (without ensiling) and silages were used for LAB isolation.

Experiment 2: Two target LAB species (L. brevis and $P$. acidilactici) were isolated in Exp. 1. Using these isolates, Italian ryegrass silage and whole crop maize silage were prepared to evaluate their inhibitory activities against aerobic deterioration. Italian ryegrass was harvested at the floweringand was wilted for $6 \mathrm{~h}$ before ensiling. The whole crop maize was cut by a precision-chop harvester at the early dough-ripe stage and ensiled with or without the addition of the isolated LAB at about $10^{6} \mathrm{cfu} / \mathrm{g}$. $P$. acidilactici and L. brevis were used as freeze-dried powders prepared using skim milk as a medium. Wilted Italian ryegrass $(300 \mathrm{~g})$ and whole crop maize (300 g) were chopped and ensiled in separate triplicate laboratory plastic pouches after the following treatments: i) Untreated; ii) $1 \times 10^{6} \mathrm{cfu}$ of $L$. brevis/g of fresh forage (LB); iii) $1 \times 10^{6} \mathrm{cfu}$ of $P$. acidilactici/g of fresh forage (PA); iv) $1 \times 10^{6} \mathrm{cfu}$ of $L$. brevis and $1 \times 10^{6}$ cfu of $P$. acidilactici/g of fresh forage (PALB). Triplicate silos were made using the same procedures as those in Exp. 1, except that the silages were stored at ambient temperature for 30 days.

\section{Analyses}

Chemical composition and live microorganisms: The DM content of the materials and silages was determined by freeze drying in experiment 1 and by oven drying at $60^{\circ} \mathrm{C}$ for $48 \mathrm{~h}$ in Exp. 2. Fermentation products in silage were determined from cold-water extracts (Nishino et al., 2003b). Silage $(20 \mathrm{~g})$ was homogenized with $180 \mathrm{~mL}$ of distilled water, and the filtrate was used for $\mathrm{pH}$ and lactic acid determinations. Volatile fatty acids and alcohols were quantitatively separated by a gas chromatograph (GC-14A, Shimadzu Co. Ltd., Kyoto, Japan) equipped with a glass capillary column coated with polyethylene glycol terephthalic acid modified (TC-FFAP, GL Sciences, Tokyo, Japan). Samples were ion exchanged with Amberlite IR120B (H+ form, Organo Co. Ltd., Tokyo, Japan). Helium was used as the carrier gas at a pressure of $0.5 \mathrm{~kg} / \mathrm{cm}$. The temperatures of the injector and detector were set at $180^{\circ} \mathrm{C}$ and $200^{\circ} \mathrm{C}$, respectively and that of the column oven was programmed at $80^{\circ} \mathrm{C}$ for the first $2 \mathrm{~min}$, and then increased to $200^{\circ} \mathrm{C}$ at a rate of $10^{\circ} \mathrm{C} / \mathrm{min}$.

Enumeration of LAB and yeasts was made using de Man, Rogosa and Sharpe (MRS) agar and potato dextrose agar, respectively (Nishinoet al., 2007). The plates from serial dilutions were incubated at $30^{\circ} \mathrm{C}$ for 3 days. The $\mathrm{pH}$ of potato dextrose agar was adjusted to 3.5 by adding sterilized lactic acid solution after autoclaving.

Aerobic stability: After the pouches of silage were completely opened in Exp. 2, half ofthe contents (150 g) were put into polyethylene bottles $(500 \mathrm{~mL})$ without compaction. The top of the bottle was kept uncovered and exposed to air for $7 \mathrm{~d}$ in a room maintained at $25^{\circ} \mathrm{C}$. A conventional thermometer was placed in the center of the silage, and the temperature was recorded at $12 \mathrm{~h}$ intervals. Aerobic deterioration was judged to have started when the temperature reached $2^{\circ} \mathrm{C}$ above the ambient temperature (Nishino et al., 2004).

Lactic acid bacteria isolation and $16 S$ rDNA preparation: From the TMR mixture and triplicate silages prepared in Exp. 1, a total of 70 LAB colonies (10 colonies from each sample) were isolated. The LAB species were purified by successive incubation in MRS broth and cells grown for $24 \mathrm{~h}$ before DNA extraction. The bacterial pellet was obtained by centrifugation at $8,000 \times \mathrm{g}$ for $15 \mathrm{~min}$ at $4^{\circ} \mathrm{C}$ and was then treated with lysozyme, proteinase $\mathrm{K}$ and RNase. The protein was removed by phenol extraction and then the DNA was precipitated with $700 \mathrm{~mL} / \mathrm{L}$ ethanol. Amplification of $16 \mathrm{~S}$ rDNA was carried out using the forward primer $27 f\left(5^{\prime}\right.$-AGAGTTTGATCCTGGCTCAG-3') 
and the reverse primer 1492r (5'-GGCTACCTTG TTACGACTT- $3^{\prime}$ ) in the reaction mixture described above. Polymerase chain reaction (PCR) was run with an initial denaturation at $96^{\circ} \mathrm{C}$ for $1 \mathrm{~min}, 25$ cycles of denaturation at $96^{\circ} \mathrm{C}$ for $10 \mathrm{~s}$, annealing at $55^{\circ} \mathrm{C}$ for $10 \mathrm{~s}$, an extension at $72^{\circ} \mathrm{C}$ for $1 \mathrm{~min}$, with a final extension at $72^{\circ} \mathrm{C}$ for $5 \mathrm{~min}$.

Sequence analyses of DNA: The PCR products were purified using a commercial cleanup kit (GENECLEAN Kit, MP Biomedicals, Solon, OH, USA). Sequencing was carried out using the Big Dye Terminator v3.1 Cycle Sequencing kit in combination with the ABI PRISM 310A automated sequencing system (Applied Biosystems, Foster City, CA, USA). Searches in the GenBank database using the BLAST program were performed to determine the closest relatives of the $16 \mathrm{~S}$ rDNA sequences.

\section{Data analysis}

The data from ryegrass and crop silages (Exp. 2) were analyzed using one-way analysis of variance with the numbers of inoculated $\mathrm{LAB}$ species as the independent variable. Differences due to treatments were assessed using Tukey's multiple comparison. Statistical analysis was performed using JMP IN software (v.5.1.2 for Windows,
SAS Institute Japan, Tokyo, Japan).

\section{RESULTS}

\section{Experiment 1}

The DM content of the SC-TMR materials was $556 \mathrm{~g} / \mathrm{kg}$ (Table 1). The LAB numbers detected were at levels of about $10^{4} \mathrm{cfu} / \mathrm{g}$ in the material with yeasts at $10^{3} \mathrm{cfu} / \mathrm{g}$. The production of lactic acid was high and that of acetic acid and ethanol low in all silages, while the levels were higher in 14-d than 56-d silage. The numbers of LAB decreased from $10^{8} \mathrm{cfu} / \mathrm{g}$ for $14-\mathrm{d}$ ensiling to $10^{6} \mathrm{cfu} / \mathrm{g}$ for $56-\mathrm{d}$ ensiling. No yeasts were detected at $14 \mathrm{~d}$ but increased to approximately $10^{2} \mathrm{cfu} / \mathrm{g}$ when ensiling continued to 56 days. From the TMR mixture and triplicate silages prepared in Exp. 1, a total of 70 LAB colonies (10 colonies from each sample) were isolated. L. plantarum (4/9 samples), $L$. fermentum (4/9) and $S$. bovis (1/9) were isolated from the untreated materials. L. plantarum (6/30 samples) and $L$. pseudomesenteroides (24/30) were found in 14-d silage. Five different species were identified as dominant LAB in SC-TMR silage opened at 56 d. P. acidilactici $(10 / 30$ samples), L. paracasei (9/30), L. brevis (10/30) and $L$.

Table 1. Chemical composition, microbial counts, fermentation products and isolated culturable lactic acid bacteria of total mixed ration silage prepared with soybean curd residue

\begin{tabular}{|c|c|c|}
\hline & Mean \pm SD & Isolated lactic acid bacteria \\
\hline \multicolumn{3}{|l|}{ Material (non-ensiled) } \\
\hline Dry matter $(\mathrm{g} / \mathrm{kg})$ & 556 & Lactobacillus plantarum (4/9) \\
\hline Crude protein (g/kg DM) & 146 & Lactobacillus fermentum (4/9) \\
\hline $\mathrm{pH}$ & 5.58 & Streptococcus bovis $(1 / 9)$ \\
\hline Lactic acid (g/kg DM) & 1.26 & \\
\hline Acetic acid (g/kg DM) & 1.26 & \\
\hline Ethanol (g/kg DM) & 16.9 & \\
\hline Soluble sugars $(\mathrm{g} / \mathrm{kg} \mathrm{DM})$ & 137 & \\
\hline Lactic acid bacteria (log cfu/g) & 3.94 & \\
\hline Yeasts $(\log \mathrm{cfu} / \mathrm{g})$ & 3.26 & \\
\hline \multicolumn{3}{|l|}{ Ensiling for 14 days } \\
\hline $\mathrm{pH}$ & $3.99 \pm 0.02$ & Lactobacillus plantarum $(6 / 30)$ \\
\hline Lactic acid (g/kg DM) & $38.3 \pm 0.87$ & Leuconostoc pseudomesenteroides (24/30) \\
\hline Acetic acid (g/kg DM) & $12.8 \pm 0.30$ & \\
\hline Ethanol (g/kg DM) & $17.9 \pm 0.57$ & \\
\hline Lactic acid bacteria (log cfu/g) & $8.32 \pm 0.15$ & \\
\hline Yeasts $(\log \mathrm{cfu} / \mathrm{g})$ & $<2$ & \\
\hline \multicolumn{3}{|l|}{ Ensiling for 56 days } \\
\hline $\mathrm{pH}$ & $3.91 \pm 0.03$ & Pediococcus acidilactici (10/30) \\
\hline Lactic acid (g/kg DM) & $34.2 \pm 0.41$ & Lactobacillus brevis $(10 / 30)$ \\
\hline Acetic acid (g/kg DM) & $16.5 \pm 0.32$ & Lactobacillus paracasei $(9 / 30)$ \\
\hline Ethanol (g/kg DM) & $20.7 \pm 0.14$ & Lactobacillus plantarum $(1 / 30)$ \\
\hline Lactic acid bacteria (log cfu/g) & $6.28 \pm 0.03$ & \\
\hline Yeasts (log cfu/g) & $2.26 \pm 0.09$ & \\
\hline
\end{tabular}

SD, standard deviation; DM, dry matter.

Silage date are means of triplicate silos. Rations in parentheses indicate how frequently the species were detected. 
Table 2. Chemical composition and microbial composition of Italian ryegrass and whole crop corn

\begin{tabular}{lcc}
\hline Item & Italian ryegrass & Whole crop corn \\
\hline Dry matter $(\mathrm{g} / \mathrm{kg})$ & 476 & 347 \\
$\mathrm{pH}$ & 5.82 & 5.46 \\
Lactic acid bacteria $(\log \mathrm{cfu} / \mathrm{g})$ & $<2$ & 6.48 \\
Yeasts $(\log \mathrm{cfu} / \mathrm{g})$ & 6.69 & 5.48 \\
Enterobacteria $(\log \mathrm{cfu} / \mathrm{g})$ & 4.62 & 6.81 \\
\hline
\end{tabular}

Data are means of duplicate analyses.

plantarum (1/30) were detected in 56-d silage and assumed to be involved in the development of resistance to aerobic deterioration in SC-TMR silage.

\section{Experiment 2}

A relatively high DM content $(476 \mathrm{~g} / \mathrm{kg}$ ) for ensiling was obtained after field wilting of Italian ryegrass (Table 2). The counts of epiphytic LAB were below the detectable level $\left(10^{2} \mathrm{cfu} / \mathrm{g}\right)$ in the pre-ensiled Italian ryegrass material. A medium DM content $(347 \mathrm{~g} / \mathrm{kg}$ ) was observed in the preensiled whole crop maize (Table 2). The counts of epiphytic $\mathrm{LAB}$, yeast and enterobacteria were approximately $10^{6}$ $\mathrm{cfu} / \mathrm{g}$ in the whole crop maize material.

The untreated ryegrass silage had lactic acid and acetic acid contents of 2.46 and $4.15 \mathrm{~g} / \mathrm{kg} \mathrm{DM}$, respectively (Table 3). The ethanol and 2, 3-butanediol contents were determined as 21.4 and $37.3 \mathrm{~g} / \mathrm{kg} \mathrm{DM}$, respectively, dominating the fermentation of untreated ryegrass silage. A small amount of propionic acid was also detected in untreated silage. A large number of enterobacteria $\left(>10^{7}\right.$ $\mathrm{cfu} / \mathrm{g}$ ) was found in the untreated ryegrass silage. The number of LAB was $10^{7} \mathrm{cfu} / \mathrm{g}$ and of yeasts approximately $10^{2} \mathrm{cfu} / \mathrm{g}$. Benefits were found when the silage was inoculated with $P$. acidilactici. One example was the rapid production of lactic acid with contents of $31.9 \mathrm{~g} / \mathrm{kg} \mathrm{DM}$ as well as ethanol and 2, 3-butanediol contents of 6.50 and $3.40 \mathrm{~g} / \mathrm{kg} \mathrm{DM}$, respectively. The 2, 3-butanediol production was inhibited to about one-tenth by $P$. acidilactici inoculation compared with the untreated control. The acetic acid content was increased to $13.5 \mathrm{~g} / \mathrm{kg}$ DM by $P$. acidilactici inoculation. The number of LAB was as high as $10^{8} \mathrm{cfu} / \mathrm{g}$ but no yeasts or enterobacteria were detected in $P$. acidilactici-inoculated silage. Inoculation with $L$. brevis also increased the lactic acid content and decreased the ethanol content compared with the untreated control. The lactic acid content was $19.8 \mathrm{~g} / \mathrm{kg} \mathrm{DM}$, lower than with $P$. acidilactici-inoculated silage. The ethanol and 2, 3butanediol contents were similar for both L. brevisinoculated and P. acidilactici-inoculated silage. Acetic acid was the main product of $L$. brevis-inoculated silage with a content of $31.5 \mathrm{~g} / \mathrm{kg} \mathrm{DM}$. The growth of yeasts and enterobacteria was inhibited by this hetero-fermentative

Table 3. Chemical composition and microbial counts of wilted Italian ryegrass silage inoculated with and without Pediococcus acidilactici $(\mathrm{PA})$ and Lactobacillus brevis (LB)

\begin{tabular}{|c|c|c|c|c|c|}
\hline Item & Control & PA & LB & $\mathrm{PA}+\mathrm{LB}$ & SE \\
\hline \multicolumn{6}{|l|}{ At silo opening } \\
\hline Dry matter $(\mathrm{g} / \mathrm{kg})$ & 426 & 429 & 444 & 442 & 0.60 \\
\hline $\mathrm{pH}$ & $5.66^{\mathrm{a}}$ & $3.76^{\mathrm{c}}$ & $3.92^{b}$ & $3.88^{\mathrm{b}}$ & 0.02 \\
\hline Lactic acid (g/kg DM) & $2.46^{\mathrm{c}}$ & $31.9^{\mathrm{a}}$ & $19.8^{\mathrm{b}}$ & $20.9^{\mathrm{b}}$ & 0.52 \\
\hline Ethanol (g/kg DM) & $21.4^{\mathrm{a}}$ & $6.50^{\mathrm{b}}$ & $8.40^{\mathrm{b}}$ & $6.61^{\mathrm{b}}$ & 1.38 \\
\hline Acetic acid (g/kg DM) & $4.15^{\mathrm{d}}$ & $13.5^{\mathrm{c}}$ & $31.5^{\mathrm{a}}$ & $26.2^{\mathrm{b}}$ & 1.28 \\
\hline 2,3-butanediol (g/kg DM) & $37.3^{\mathrm{a}}$ & $3.40^{\mathrm{b}}$ & $0.54^{\mathrm{b}}$ & $0.48^{\mathrm{b}}$ & 0.55 \\
\hline Propionic acid (g/kg DM) & 1.83 & 0.79 & 0.18 & 0.14 & 0.24 \\
\hline Lactic acid bacteria (log cfu/g) & $7.08^{c}$ & $8.35^{\mathrm{a}}$ & $7.89^{\mathrm{b}}$ & $7.68^{\mathrm{b}}$ & 0.08 \\
\hline Yeasts (log cfu/g) & 2.90 & $<2.00$ & $<2.00$ & $<2.00$ & - \\
\hline Enterobacteria $(\log \mathrm{cfu} / \mathrm{g})$ & 7.99 & $<2.00$ & $<2.00$ & $<2.00$ & - \\
\hline \multicolumn{6}{|l|}{ After aerobic exposure } \\
\hline Dry matter $(\mathrm{g} / \mathrm{kg})$ & $409^{c}$ & $445^{\mathrm{b}}$ & $463^{\mathrm{a}}$ & $466^{\mathrm{a}}$ & 0.36 \\
\hline $\mathrm{pH}$ & $6.70^{\mathrm{a}}$ & $3.82^{\mathrm{c}}$ & $4.00^{\mathrm{b}}$ & $3.99^{\mathrm{b}}$ & 0.02 \\
\hline Lactic acid (g/kg DM) & $0.51^{\mathrm{c}}$ & $37.5^{\mathrm{a}}$ & $24.0^{\mathrm{b}}$ & $26.4^{\mathrm{b}}$ & 1.52 \\
\hline Ethanol (g/kg DM) & $0.78^{\mathrm{b}}$ & $2.79^{\mathrm{ab}}$ & $4.45^{\mathrm{a}}$ & $2.96^{\mathrm{ab}}$ & 0.66 \\
\hline Acetic acid (g/kg DM) & $2.71^{\mathrm{c}}$ & $14.0^{\mathrm{b}}$ & $29.8^{\mathrm{a}}$ & $33.9^{\mathrm{a}}$ & 1.59 \\
\hline 2,3-butanediol (g/kg DM) & $3.64^{\mathrm{a}}$ & $4.56^{\mathrm{a}}$ & $0.39^{\mathrm{b}}$ & $0.32^{\mathrm{b}}$ & 0.16 \\
\hline Propionic acid (g/kg DM) & 1.20 & 0.70 & 0.26 & 0.21 & 0.20 \\
\hline Lactic acid bacteria (log cfu/g) & $8.30^{\mathrm{a}}$ & $7.42^{\mathrm{ab}}$ & $5.94^{c}$ & $6.61^{\mathrm{bc}}$ & 0.22 \\
\hline Yeasts $(\log \mathrm{cfu} / \mathrm{g})$ & 7.66 & 6.39 & $<2.00$ & $<2.00$ & - \\
\hline Enterobacteria $(\log \mathrm{cfu} / \mathrm{g})$ & 6.90 & $<2.00$ & $<2.00$ & $<2.00$ & - \\
\hline
\end{tabular}

SE, standard error; DM, dry matter.

Mean of triplicate silages. Values within the same row followed by different superscript letters are significantly different ( $p<0.05$ ). 
$\mathrm{LAB}$ and the numbers of $\mathrm{LAB}$ increased in $L$. brevisinoculated compared to the control silage. Silage inoculated with both $P$. acidilactici and $L$. brevis exhibited similar fermentation profiles to silages inoculated with $L$. brevis alone. Aerobic stability was undoubtedly higher in the inoculated silage treatments (Table 3). When untreated silage was exposed to air, the $\mathrm{pH}$ increased to over 6.7 and the fermentation products decreased to almost negligible levels and heating appeared at day 2. No distinct heating was found during the 7-d test (Table 4) and the stability was not affected by the inoculants. In inoculated silage, the $\mathrm{pH}$ value and acetic acid content remained unchanged but the lactic acid content increased after $7 \mathrm{~d}$. However, a large increase in yeasts was found in P. acidilactici-treated silage and acetic acid content increased in the combination-treated silage.

All maize silage showed a low $\mathrm{pH}$ of 3.70 with lactic acid dominating the fermentation products regardless of the LAB inoculated (Table 5). The lactic and acetic acid contents were also similar between untreated and inoculated silages. Adding L. brevis lowered the lactic acid and ethanol contents and increased the acetic acid content in maize silage. Inoculation with $P$. acidilactici did not affect the fermentation of maize silage, whereas yeast counts were slightly decreased by $P$. acidilactici and combined inoculations. After $7 \mathrm{~d}$, neither P. acidilactici nor L. brevis could prevent spoilage if inoculated alone, but the deterioration was suppressed by a combined inoculation of both LABs. Aerobic deterioration occurred within $7 \mathrm{~d}$ in all treatments after exposure to air. The combined inoculation silage resisted deterioration for more than 6 days in the
Table 4. The days of aerobic stability of Italian ryegrass and whole crop corn silage inoculated with and without Pediococcus acidilactici (PA) and Lactobacillus brevis (LB)

\begin{tabular}{lcccc}
\hline Item & Control & PA & LB & PA+LB \\
\hline Italian ryegrass silage & 2 & $>7$ & $>7$ & $>7$ \\
Whole crop cron & 1 & 2 & 2.5 & 5.5 \\
\hline
\end{tabular}

Data are means of duplicate analyses.

presence of air. The $\mathrm{pH}$ was more than 6.0 in all treatments except for combined inoculation of the two LABs. The $\mathrm{pH}$ was 4.5 for the combined silage. In the control, $P$. acidilactici and $L$. brevis silages, the lactic acid content decreased by more than $90 \%$ compared with the initial values immediately after opening the silos. However, in the combined treatment, the lactic acid content fell to $50 \%$. Very little acetic acid remained after 7 days in any treatment. Both yeasts and LAB levels increased after the silos were opened.

\section{DISCUSSION}

Our previous investigations have shown that TMR silage can resist aerobic deterioration when prepared with SC after being ensiled for 2 months (Wang and Nishino, 2008a; Wang and Nishino, 2009). In the present study, SCcontaining TMR silage was prepared to provide materials from which predominant LAB could be isolated. The LAB grown on MRS agar were isolated and their DNA was purified. The species were then identified according to $16 \mathrm{~S}$ rDNA sequences. The results showed that the dominant bacteria changed during storage. The fermentation was

Table 5. Chemical composition and microbial counts of whole crop corn silage inoculated with and without Pediococcus acidilactici (PA) and Lactobacillus brevis (LB)

\begin{tabular}{|c|c|c|c|c|c|}
\hline Item & Control & PA & LB & $\mathrm{PA}+\mathrm{LB}$ & SE \\
\hline \multicolumn{6}{|l|}{ At silo opening } \\
\hline Dry matter (g/kg) & 282 & 297 & 276 & 309 & 6.94 \\
\hline $\mathrm{pH}$ & 3.70 & 3.68 & 3.67 & 3.71 & 0.01 \\
\hline Lactic acid (g/kg DM) & 69.9 & 62.6 & 64.1 & 59.6 & 1.96 \\
\hline Acetic acid (g/kg DM) & $29.4^{\mathrm{b}}$ & $26.0^{\mathrm{b}}$ & $36.9^{\mathrm{ab}}$ & $40.5^{\mathrm{a}}$ & 2.01 \\
\hline Ethanol (g/kg DM) & $22.1^{\mathrm{a}}$ & $22.9^{\mathrm{a}}$ & $17.7^{\mathrm{b}}$ & $14.4^{\mathrm{b}}$ & 1.28 \\
\hline Lactic acid bacteria $(\log \mathrm{cfu} / \mathrm{g})$ & $5.89^{\mathrm{b}}$ & $6.30^{\mathrm{ab}}$ & $6.01^{\mathrm{ab}}$ & $6.60^{\mathrm{a}}$ & 0.13 \\
\hline Yeasts (log cfu/g) & $5.96^{\mathrm{a}}$ & $5.42^{\mathrm{b}}$ & $5.99^{\mathrm{a}}$ & $5.42^{\mathrm{b}}$ & 0.12 \\
\hline \multicolumn{6}{|l|}{ After aerobic exposure } \\
\hline Dry matter $(\mathrm{g} / \mathrm{kg})$ & $348^{\mathrm{b}}$ & $362^{\mathrm{a}}$ & $342^{\mathrm{b}}$ & $368^{\mathrm{a}}$ & 12.4 \\
\hline $\mathrm{pH}$ & $6.17^{\mathrm{a}}$ & $6.17^{\mathrm{a}}$ & $6.03^{\mathrm{a}}$ & $4.45^{\mathrm{b}}$ & 0.08 \\
\hline Lactic acid (g/kg DM) & $1.72^{\mathrm{b}}$ & $2.76^{\mathrm{b}}$ & $3.80^{\mathrm{b}}$ & $23.9^{\mathrm{a}}$ & 1.84 \\
\hline Acetic acid (g/kg DM) & 1.15 & 0.83 & 1.17 & 1.90 & 0.22 \\
\hline Ethanol (g/kg DM) & $0.14^{\mathrm{b}}$ & $0.11^{\mathrm{b}}$ & $0.56^{\mathrm{ab}}$ & $1.52^{\mathrm{a}}$ & 0.13 \\
\hline Lactic acid bacteria (log cfu/g) & 8.85 & 8.83 & 8.91 & 8.51 & 0.12 \\
\hline Yeasts (log cfu/g) & 8.83 & 8.87 & 8.82 & 8.59 & 0.10 \\
\hline
\end{tabular}

SE, standard error; DM, dry matter.

Mean of triplicate silages. Values within the same row followed by different superscript letters are significantly different $(\mathrm{p}<0.05)$. 
initiated by homo-fermentative strain ( $L$. LAB (L. plantarum), but after 56 days, the dominant bacteria in the SC-TMR silage had become $P$. acidilactici, $L$. paracasei and L. brevis. These results suggest that three LABs (P. acidilactici, L. paracasei, and L. brevis) were involved in the stability of SC-TMR silage. In the process of forage ensiling, lactic acid-producing cocci, e.g., streptococci, leuconostocs, pediococci, lactococci, and enterococci, have been shown to grow vigorously in the early stages of the ensiling process, while lactobacilli would overwhelm the population when prolonged ensiling is made (Cai, 2001). This was not necessarily true with the microflora of SC-TMR silage. Three LABs (P. acidilactici, $L$. paracasei, and L. brevis) have often been isolated from crop silages, and thus can be considered as usual ones (Cai, 2001). None of them improved stability when inoculated alone (Adesoganet al., 2003; Danner et al., 2003; Wang and Nishino, 2008c), and no metabolites were found that could inhibit the growth of yeasts and molds. Even so, strain difference might exist in the ability to inhibit spoilage, thereby inoculation experiment may better be conducted by using strains isolated from stable TMR silage. In addition, it is difficult to understand the significance of the species for silage preservation because experiments involving single species alone do not indicate their contribution to the silage of the various species when combined. There might have been synergy between hetero-fermentative LAB and homofermentative $\mathrm{LAB}$ but the effect would need to be confirmed experimentally by inoculation with aerobically unstable silages. $P$. acidilactici was a potential silage additive (Fitzsimons et al., 1992). Inoculation of $P$. acidilactici was shown to increase lactate production and improve DM recovery, while its response was not necessarily consistent. L. brevis was the predominant heterofermentative LAB. It was reported that application of $L$. brevis enhances acetate production to retard aerobic spoilage in maize silage (Danner et al., 2003). L. brevis and $P$. acidilactici are worth to be confirmed by inoculation with aerobically unstable silage. In the present study, the inoculation experiments were made using Italian ryegrass and whole crop maize to ascertain the ability of the LAB to inhibit aerobic deterioration. Italian ryegrass and whole crop maize are suitable crops for this purpose, because the silage is known to be the most liable to spoilage on exposure to air.

Based on the Italian ryegrass inoculation experiment, $P$. acidilactici has the potential to inhibit aerobic deterioration. It is difficult to explain why considerable deterioration did not occur in silages inoculated with $P$. acidilactici because it has been reported that several homo-fermentative LABinoculated silages have tended to spoil even more rapidly than the control silage as a result of the insufficient production of volatile fatty acids (Rust et al., 1989; Weinberg et al., 1993; Muck and Kung, 1997). Stability was greatly improved in L. brevis-inoculated silage, but the high stability was not caused by an increase in acetic acid content (Adesogan et al., 2003). The results of the present study were different to those of Adesogan et al. (2003) and Danner et al. (2003) who reported that L. brevis could not improve stability when inoculated alone. Therefore there could be certain substances that can suppress fungal growth in silages inoculated with P. acidilactici and L. brevis.

In whole crop maize silages, the inoculants did not affect the fermentation significantly, probably because of the higher numbers of epiphytic LAB and the good ensiling characteristics of this crop. The counts of epiphytic LAB, yeast and enterobacteria were approximately $10^{6} \mathrm{cfu} / \mathrm{g}$ in the maize material (Table 2).Therefore, the bacteria in the inoculants did not have the opportunity to dominate the ensiling process or to exert an effect on the fermentation before the $\mathrm{pH}$ declined to conditions that kept the silages stable. Bolsen et al. (1989) concluded that whole-plant maize fermented rapidly and that bacterial inoculants had little effect on the rate and efficiency of the silage fermentation. Aerobic deterioration occurred within $7 \mathrm{~d}$ in all treatments in the present study but the combined inoculation silage resisted deterioration. These results have shown that a synergistic effect may exist which inhibits silage deterioration by using the homo-fermentative $P$. acidilactici and the hetero-fermentative L. brevis. The substances accounting for the inhibition remain to be identified and the synergistic effects that are suggested to be involved in the stability of SC-TMR silage need further elucidation.

\section{CONCLUSION}

The results have shown that $P$. acidilactici and L. brevis were the dominant bacteria in SC-TMR silage. Using inoculation experiments with $P$. acidilactici and $L$. brevis on Italian ryegrass and whole crop maize silage, a synergistic effect may have been detected which inhibits the deterioration of SC-TMR silage. This synergistic effect was especially evident in the aerobic stability test. The present study may be the first to report the existence of a synergistic effect inhibiting the deterioration of silage by using different LAB. Further studies are needed to confirm the identity of the substances accounting for this inhibition, which may be useful for developing potential antifungal agents.

\section{CONFLICT OF INTEREST}

We certify that there is no conflict of interest with any 
financial organization regarding the material discussed in the manuscript.

\section{ACKNOWLEDGMENTS}

The work was supported by National Natural Science Foundation of China (Grant No. 31402136), the Foundation for Sci. \& Tech. Research Project of Heilongjiang Province of China (Grant No. WB13B111) and Scientific Research Foundation for the Returned Overseas Chinese Scholars, State Educational Commission of Heilongjiang Province of China (No. 1252HQ009).

\section{REFERENCES}

Adesogan, A. T., M. B. Salawu, A. B. Ross, D. R. Davies, and A. E. Brooks. 2003. Effect of Lactobacillus buchneri, Lactobacillus fermentum, Leuconostoc mesenteroides inoculants, or a chemical additive on the fermentation, aerobic stability, and nutritive value of crimped wheat grains. J. Dairy Sci. 86:1789-1796.

Bolsen, K. K., A. Laytimi, R. A. Hart, L. Nuzback, and F. Niroomand. 1989. Effect of commercial inoculants on fermentation of 1987 and 1988 Kansas silage crops. In: Food for Thought. Pioneer Hi-bred Int. Inc., Des Moines, IA, USA.

Cai, Y. 2001. The role of lactic acid bacteria in the preparation of high fermentation quality. Grassl. Sci. 47:527-533.

Danner, H., M. Holzer, E. Mayrhuber, and R. Braun. 2003. Acetic acid increases stability of silage under aerobic conditions. Appl. Environ. Microbiol. 69:562-567.

Driehuis, F. and S. J. W. H. Oude Elferink. 2000. The impact of the quality of silage on animal health and food safety: A review. Vet. Q. 22:212-216.

Fitzsimons, A., F. Duffner, D. Curtin, G. Brophy, P. Okiely, and O. Connell. 1992. Assessment of Pediococcus acidilacticias a potential silage inoculant. Appl. Environ. Microbiol. 58:30473052.

Muck, R. E. and L. Jr. Kung. 1997. Effects of silage additives on ensiling. In: Silage: Field to feed bunk. NRAES-99, Ithaca, NY, USA. pp. 187-199.
Nishino, N., H. Harada, and E. Sakaguchi. 2003a. Evaluation of fermentation and aerobic stability of wet brewers' grains ensiled alone or in combination of various feeds as a total mixed ration. J. Sci. Food Agric. 83:557-563.

Nishino, N., M. Yoshida, H. Shiota, and E. Sakaguchi. 2003 b. Accumulation of 1,2-propanediol and enhancement of aerobic stability in whole crop maize silage inoculated with Lactobacillus buchneri. J. Appl. Microbiol. 94:800-807.

Nishino, N., H. Wada, M. Yoshida, and H. Shiota. 2004. Microbial counts, fermentation products, and aerobic stability of whole crop corn and a total mixed ration ensiled with and without inoculation of Lactobacillus casei or Lactobacillus buchneri. J. Dairy Sci. 87:2563-2570.

Nishino, N., H. Hattori, H. Wada, and E. Touno. 2007. Biogenic amine production in grass, maize and total mixed ration silages inoculated with Lactobacillus casei or Lactobacillus buchneri. J. Appl. Microbiol. 103:325-332.

Niwa, Y. 2001. Silage making and utilization of high-moisture byproducts. 4. Making silage from tofu cake and utilization. Grassl. Sci. 47:323-326.

Rust, S. R., H. S. Kim, and G. L. Enders. 1989. Effects of a microbial inoculant on fermentation characteristics and nutritional value of corn silage. J. Prod. Agric. 2:235-241.

Wang, F. and N. Nishino. 2008a. Ensiling of soybean curd residue and wet brewers grains with or without other feeds as a total mixed ration. J. Dairy Sci. 91:2380-2387.

Wang, F. and N. Nishino. 2008b. Resistance to aerobic deterioration of total mixed ration silage: Effect of ration formulation, air infiltration and storage period on fermentation characteristics and aerobic stability. J. Sci. Food Agric. 88:133140

Wang, F. and N. Nishino. 2008c. Effect of aerobic exposure after silo opening on feed intake and digestibility of total mixed ration silage containing wet brewers grains or soybean curd residue. Grassl. Sci. 54:164-166.

Wang, F. and N. Nishino. 2009. Association of Lactobacillus buchneri with aerobic stability of total mixed ration containing wet brewers grains preserved as a silage. Anim. Feed Sci. Technol. 149:265-274.

Weinberg, Z. G., G. Ashbell, Y. Hen, and A. Azriel. 1993. The effect of applying lactic acid bacteria at ensiling on the aerobic stability of silages. J. Appl. Microbiol.75:512-518. 